\title{
The Role of Colletotrichum spp. in Postharvest Anthracnose of Citrus and Survival of $C$. acutatum on Fruit
}

L. W. Timmer, Professor, Citrus Research and Education Center, University of Florida; G. E. Brown, Research Scientist III, Florida Department of Citrus, Lake Alfred 33850; and S. E. Zitko, Senior Biologist, Citrus Research and Education Center, University of Florida, Lake Alfred 33850

\begin{abstract}
Timmer, L. W., Brown, G. E., and Zitko, S. E. 1998. The role of Colletotrichum spp. in postharvest anthracnose of citrus and survival of $C$. acutatum on fruit. Plant Dis. 82:415-418.

Colletotrichum gloeosporioides causes postharvest anthracnose of citrus fruit and is a common saprobe in citrus groves, whereas $C$. acutatum infects flower petals and causes postbloom fruit drop (PFD). The purpose of this study was to determine whether $C$. acutatum caused anthracnose, survived as quiescent infections on fruit, and represented a threat for introduction of the PFD pathogen to disease-free areas. When Robinson tangerine fruit were artificially inoculated with both species and exposed to high levels of ethylene, only fruit inoculated with $C$. gloeosporioides developed postharvest anthracnose. However, C. acutatum was readily reisolated from inoculation sites on asymptomatic fruit. Navel oranges harvested from groves with severe PFD the previous spring developed low levels of anthracnose, but only C. gloeosporioides was isolated from lesions. Valencia orange fruit harvested at bloom during a PFD outbreak had high surface populations of $C$. acutatum which declined rapidly during 2 to 3 weeks of storage. Quiescent infections formed on artificially inoculated and naturally exposed fruit were reduced but not eliminated by washing, waxing, and fungicide treatment in the packinghouse. Since $C$. acutatum does not produce postharvest anthracnose, the risk of introduction of this pathogen to disease-free areas is minimal. However, if fruit were harvested during a PFD outbreak, $C$. acutatum might survive standard packinghouse treatment and shipment as quiescent infections.
\end{abstract}

Additional keyword: Colletotrichum gloeosporioides

Colletotrichum spp. cause anthracnose disease and postharvest decays on many tropical, subtropical, and temperate fruits $(4,9,13)$. Many of these diseases are caused by $C$. gloeosporioides (13) but, in recent years, C. acutatum has been found to be an important pathogen of these fruits $(4,8,9)$. This species has been reported on peaches, apples, and pecans (4) and on strawberries (8). On some hosts, more than one species cause disease. For example, C. gloeosporioides, C. acutatum, and C. fragariae all cause strawberry anthracnose (8).

On citrus, postharvest anthracnose of fruit is caused by $C$. gloeosporioides (Penz.) Penz. \& Sacc. in Penz. (6,7). This species, which is a common saprobe in citrus groves, invades dead and senescent leaves, twigs, and fruit and produces acer-

Corresponding author: L. W. Timmer

E-mail: 1wt@icon.lal.ufl.edu

This study was supported in part by the Florida Citrus Production Research Advisory Council Project 961-03.

Florida Agricultural Experiment Station Journal Series No. R-05970.

Accepted for publication 30 December 1997.

Publication no. D-1998-0209-01R

(C) 1998 The American Phytopathological Society vuli with abundant conidia on dead tissues of citrus. Conidia are splash-dispersed to living leaves, twigs, and fruit, where they germinate to produce appressoria and quiescent infections $(6,14)$. Once the tissue dies, it is rapidly colonized and acervuli are formed, completing the life cycle.

When fruit with immature rinds with high numbers of appressoria of $C$. gloeosporioides are exposed to stress, the rind collapses and is colonized by the fungus, producing postharvest anthracnose $(6,7)$. Early-season fruit is especially susceptible to anthracnose, and disease severity is greatly increased by exposure to high levels of ethylene for degreening. Washing of the fruit prior to degreening removes many appressoria and reduces disease incidence. Preharvest sprays of benomyl and postharvest fruit drenches with thiabendazole (TBZ) are effective in reducing the disease $(6,10)$.

C. acutatum Simmonds causes postbloom fruit drop (PFD) of all citrus species as well as anthracnose of Key lime, on which it affects immature leaves, fruit, and flowers $(3,5)$. In PFD, the fungus infects petals, producing lesions with acervuli and abundant conidia. Conidia are splashed from acervuli on petals to leaves, twigs, fruit, and calyces, where they germinate to form appressoria. Quiescent infections are formed on vegetative tissues in the grove and the fungus is capable of surviving for months in that state $(2,3,15)$. In contrast to C. gloeosporioides, C. acutatum does not colonize dead tissues of citrus in the field (3). Rather, in the presence of water, appressoria on the leaf surface splashed from flower petals germinate directly and produce a few conidia $(2,12,15)$. These conidia are splash-dispersed to new flowers, which they infect, causing PFD.

PFD is known only in the Americas (11), but there is concern that the pathogen could be introduced into other citrus areas on fruit shipped to those regions. If $C$. acutatum were able to infect fruit and produce postharvest anthracnose and acervuli on the fruit surface, the risk of introducing the pathogen to new areas would be increased. The goal of this study was to determine the ability of $C$. acutatum to cause anthracnose and to survive on the surface of harvested fruit as quiescent infections.

\section{MATERIALS AND METHODS}

Artificially inoculated fruit. Fruit used in experiment 1 were from 7-year-old Robinson tangerine trees which had been sprayed with benomyl at $1.2 \mathrm{~g}$ a.i./liter, using about 5 liters/tree, on 2 July 1996 to suppress natural infection by $C$. gloeosporioides. Fruit used in experiment 2 were also Robinson tangerines, but had not received a preharvest benomyl spray. In experiment 3 , the fruit used were from 7-year-old Robinson tangerines, navel oranges, and Ruby Red grapefruit trees. The Robinson tangerines and navel oranges in this experiment received preharvest benomyl sprays as described above, but the grapefruit received no preharvest benomyl applications.

Fruit for inoculation was harvested from the grove, washed thoroughly with soap and water, and scrubbed by hand with a brush to remove as many naturally formed appressoria as possible. Fruit was disinfested for $2 \mathrm{~min}$ in $10 \%$ household bleach (0.05\% Na hypochlorite), then rinsed with sterile distilled water, and dried. For each treatment, about 15 to 20 fruit were placed in each of 3 plastic containers. Fruit was supported on a metal rack and the bottom of the container was filled to a 2-cm depth with water. An isolate of $C$. gloeosporioides from dead citrus leaves from Arcadia, Florida, and an isolate of C. acutatum from diseased flower petals from Vero Beach, Florida, were grown on potato-dextrose 
agar (PDA). Conidia were harvested from the plates using sterile distilled water, washed three times by centrifugation, and diluted to $10^{5} / \mathrm{ml}$. Two separate drops of a conidial suspension were placed on marked areas on each fruit. Fruit in experiments 1 and 3 were inoculated without wounding. In experiment 2, half of the fruit inoculated with each species were wounded by puncturing the rind at the inoculation site with a needle to a depth of about $2 \mathrm{~mm}$. The plastic containers were closed and incubated at 23 to $25^{\circ} \mathrm{C}$ for $48 \mathrm{~h}$. After incubation, representative fruit were examined microscopically. In all cases, both species had formed numerous appressoria by that time. Fruit were inoculated during the time of year when they were most susceptible to anthracnose; those in experiment 1 on 11 September 1996, those in experiment 2 on 25 September 1996, and those in experiment 3 on 9 October 1996.

After inoculation, fruit were incubated for $72 \mathrm{~h}$ at $25^{\circ} \mathrm{C}$ at close to $100 \%$ relative humidity (RH) with $50 \mu \mathrm{l} /$ liter ethylene. After removal from the ethylene chamber, fruit were incubated 2 more days at $25^{\circ} \mathrm{C}$ in experiment 1 . In experiment 2 , fruit were washed and waxed in a standard packinghouse operation, then incubated for 2 more days at $25^{\circ} \mathrm{C}$. In experiment 3 , fruit were washed and waxed using $2,000 \mu \mathrm{g} / \mathrm{ml} \mathrm{TBZ}$ in the wax in a standard packinghouse operation, then incubated 2 days at $25^{\circ} \mathrm{C}$.

Inoculated sites on all fruit were examined for the presence of anthracnose le- sions. Fruit were rated as positive for anthracnose when sunken, necrotic lesions about the size of water droplets were produced. Fruit rated as negative did not differ from the non-inoculated controls. Isolations were made from each inoculated site using the selective medium for Colletotrichum spp. developed by Agostini and Timmer (1), consisting of PDA plus copper hydroxide (42 $\mathrm{mg} \mathrm{Cu} /$ liter) and streptomycin (300 mg/liter). In experiment 1 , where fruit was not washed and waxed, rind pieces were surface-disinfested for $2 \mathrm{~min}$ in $10 \%$ household bleach $(0.05 \%$ Na hypochlorite) and rinsed in sterile distilled water prior to plating. In experiments 2 and 3 , rind pieces were plated directly without disinfestation.

Isolates recovered were tentatively identified to species by colony morphology and growth rate. Species identification was confirmed by transferring all cultures to PDA plates containing $10 \mu \mathrm{g} / \mathrm{ml}$ benomyl. C. gloeosporioides from citrus is highly sensitive to benomyl and does not grow at that concentration, whereas $C$. acutatum grows readily, albeit at a slower rate than on unamended media (11).

Natural infections from fall-harvested fruit. Fruit from navel orange groves heavily infested with PFD the previous spring were harvested in Arcadia on 17 September 1996 and in Lake Wales on 25 September 1996. All fruit were harvested from the vicinity of persistent calyces that characteristically remain on the tree as a

Table 1. Inoculation of Robinson tangerines with Colletotrichum gloeosporioides (C.g.) and C. acutatum (C.a.) to determine the ability of these two species to cause anthracnose and form quiescent infections on fruit (experiment 1)

\begin{tabular}{|c|c|c|c|c|c|}
\hline \multirow[b]{3}{*}{ Treatment $^{\mathbf{b}}$} & \multirow{3}{*}{$\begin{array}{l}\text { Inoculation sites } \\
\text { with lesions (\%) }\end{array}$} & \multicolumn{4}{|c|}{ Reisolation $(\%)^{\mathrm{a}}$} \\
\hline & & \multicolumn{2}{|c|}{ Lesions } & \multicolumn{2}{|c|}{ No lesions } \\
\hline & & C.g. & C. a. & C. g. & C. a. \\
\hline C. gloeosporioides & $48.7 \pm 4.1$ & $97.2 \pm 2.8$ & 0.0 & $77.7 \pm 9.3$ & 0.0 \\
\hline C. acutatum & 0.0 & $\ldots^{c}$ & $\ldots$ & 0.0 & $92.2 \pm 1.1$ \\
\hline Control & 0.0 & $\ldots$ & $\ldots$ & $1.1 \pm 1.1$ & 0.0 \\
\hline
\end{tabular}

${ }^{a}$ Fruit not washed or waxed prior to reisolations. Rind pieces disinfested with $10 \%$ household bleach ( $0.05 \%$ Na hypochlorite).

$\mathrm{b}$ Three replicate humid chambers with 15 fruit each were used for each treatment with two inoculation sites per fruit; means \pm standard error.

${ }^{\mathrm{c}}$ No lesions. result of postbloom fruit drop. About 400 to 600 fruit were placed in ethylene chambers at close to $100 \% \mathrm{RH}$. Half of the fruit were exposed to $10 \mu \mathrm{l} / \mathrm{liter}$ and half to 50 $\mu \mathrm{l} /$ liter ethylene for $48 \mathrm{~h}$. After removal from the ethylene chamber, fruit were washed and waxed in a standard packinghouse operation. Waxed fruit were then incubated at $21^{\circ} \mathrm{C}$ for 2 to 3 weeks, examined periodically, and the number of fruit affected by postharvest decays recorded. Isolations were made on the selective medium for Colletotrichum spp. (2) from all fruit with anthracnose symptoms. Isolates were identified as previously described.

Natural infections in spring-harvested fruit. Valencia oranges were harvested on 31 March 1997 and again on 18 April 1997 from a grove severely affected by PFD near Fort Pierce, Florida. Mature fruit were harvested from portions of trees with currently affected flowers, or near clusters of persistent calyces indicating a recent attack by $C$. acutatum. Fruit from the first harvest were maintained in a screenhouse exposed to ambient conditions for the first 11 days, then transferred to a storage room at $21^{\circ} \mathrm{C}$ and close to $100 \% \mathrm{RH}$ to prevent dehydration. Fruit from the first harvest were sampled 2, 11, and 19 days after collection for determination of surface propagule densities. Fruit from the second harvest were stored in the screenhouse under ambient conditions until sampled 5 days later to determine surface propagule densities.

For determination of surface propagule densities, on each sample date 40 fruit were scrubbed by hand using a brush with a small amount of water, and rinsed using 50 or $100 \mathrm{ml}$ tap water per fruit. One-tenth $\mathrm{ml}$ aliquots of the rinse suspension was spread on each of 5 plates for each fruit. The medium used was that of Agostini and Timmer (2), to which benomyl had been added at $10 \mu \mathrm{g}$ a.i./ml. Benomyl eliminates the growth of $C$. gloeosporioides except for occasional resistant isolates but allows growth of $C$. acutatum (11). In some cases, dodine $(400 \mu \mathrm{g} / \mathrm{ml})$ and tetracycline $(100$ $\mu \mathrm{g} / \mathrm{ml}$ ) were added to the above medium, which slowed the growth of $C$. acutatum but eliminated many fungal and bacterial

Table 2. Inoculation of Robinson tangerines with Colletotrichum gloeosporioides (C. g.) and C. acutatum (C. a.) to determine the ability of these two species to cause anthracnose and form quiescent infections on fruit (experiment 2)

\begin{tabular}{|c|c|c|c|c|c|c|}
\hline \multirow[b]{3}{*}{ Species } & \multirow[b]{3}{*}{ Fruit treatment ${ }^{\mathrm{b}}$} & \multirow[b]{3}{*}{ Inoculation sites with lesions (\%) } & \multicolumn{4}{|c|}{ Reisolation $(\%)^{\mathrm{a}}$} \\
\hline & & & \multicolumn{2}{|c|}{ Lesions } & \multicolumn{2}{|c|}{ No lesions } \\
\hline & & & C. g. & C. a. & C. g. & C. a. \\
\hline \multirow[t]{2}{*}{ C. gloeosporioides } & Non-wounded & $52.2 \pm 6.8$ & $97.0 \pm 3.0$ & 0.0 & $81.3 \pm 9.2$ & 0.0 \\
\hline & Wounded & $62.6 \pm 3.2$ & $98.2 \pm 1.8$ & 0.0 & $97.9 \pm 2.1$ & 0.0 \\
\hline \multirow[t]{2}{*}{ C. acutatum } & Non-wounded & $3.3 \pm 3.3$ & 100.0 & 0.0 & 0.0 & $66.3 \pm 11.7$ \\
\hline & Wounded & $5.7 \pm 2.2$ & 100.0 & 0.0 & 0.0 & $90.0 \pm 3.6$ \\
\hline \multirow[t]{2}{*}{ Control } & Non-wounded & 0.0 & $\ldots{ }^{\mathrm{c}}$ & $\ldots$ & $14.2 \pm 3.8$ & 0.0 \\
\hline & Wounded & 0.0 & $\ldots$ & $\ldots$ & $14.7 \pm 6.7$ & 0.0 \\
\hline
\end{tabular}

\footnotetext{
${ }^{\text {a }}$ Fruit was washed and waxed in a standard packinghouse operation prior to reisolations, but received no fungicide treatment.

${ }^{\mathrm{b}}$ Three replicate humid chambers with 15 fruit each were used for each species and for each fruit treatment with two inoculation sites per fruit; means \pm standard error; fruit was wounded by puncturing with a needle to a depth of $2 \mathrm{~mm}$.
}

${ }^{\mathrm{c}}$ No lesions. 
contaminants, thus facilitating the reading of the plates. Plates were incubated at $27^{\circ} \mathrm{C}$ for 7 to 10 days.

The fruit not used for surface propagule density determinations were washed and waxed in a standard packinghouse operation using $2 \%$ sodium orthophenylphenate (SOPP) in the wash water and $2,000 \mu \mathrm{g} / \mathrm{ml}$ each TBZ and imazalil in the wax 11 days after picking in the first harvest and 5 days after picking in the second harvest. Fruit from the second harvest were then stored for 5 weeks at $10^{\circ} \mathrm{C}$ and an additional 2 weeks at $20^{\circ} \mathrm{C}$. After storage, fruit were examined for postharvest decays and isolations were made from any fruit on which Colletotrichum spp. had developed.

The 40-fruit sample from the second sampling date of the first harvest (11 days), as well as the 40-fruit sample from the second harvest (5 days), which had been washed and waxed in a standard packinghouse operation with wash water containing $2 \%$ SOPP and wax containing 2,000 $\mu \mathrm{g} / \mathrm{ml}$ each of TBZ and imazalil, were sampled for latent infections. Forty 3-mmdiameter rind plugs were cut from each of the fruit. Rind plugs were placed flavedoside down, 5 plugs/plate, on the selective media described above without surface sterilization. Plates were incubated for 7 to 10 days at $27^{\circ} \mathrm{C}$. C. acutatum was usually distinguishable from $C$. gloeosporioides directly on the isolation plates by colony size and morphology. Where doubt existed, the growth rate on PDA and the conidial morphology were examined in comparison with known isolates for final identification.

\section{RESULTS}

Artificially inoculated fruit. In experiment 1, C. gloeosporioides caused anthracnose lesions on about half of the inoculated sites after 7 days, but $C$. acutatum produced none (Table 1). C. gloeosporioides was reisolated from virtually all of the fruit with anthracnose and from many of the inoculated fruit which formed no lesions. Despite the fact that $C$. acutatum produced no anthracnose lesions, it was reisolated from most of the inoculation sites. C. gloeosporioides was isolated from a low percentage of control fruit.

In experiment 2, C. gloeosporioides again caused anthracnose lesions on over half of the fruit and was usually reisolated from most inoculated fruit whether or not lesions were formed (Table 2). A low percentage of fruit inoculated with $C$. acutatum developed anthracnose lesions. However, all of the isolates from these lesions were $C$. gloeosporioides. $C$. acutatum was again reisolated from a high percentage of fruit without lesions inoculated with that species. Although fruit in this experiment were washed and waxed and fruit in experiment 1 were not, reisolation of $C$. acutatum was generally lower in experiment 2 than in experiment 1 . Fruit inoculated with $C$. gloeosporioides had slightly higher levels of anthracnose on wounded than on non-wounded fruit. Recovery of both species on asymptomatic fruit was also slightly higher on wounded than on non-wounded fruit. No anthracnose lesions developed on control fruit, but $C$. gloeosporioides was isolated from a low percentage of the fruit.

In experiment 3, anthracnose lesions developed on Robinson tangerines inoculated with C. gloeosporioides, but not on navel

Table 4. Recovery of Colletotrichum acutatum from naturally infested Valencia oranges harvested during an outbreak of postbloom fruit drop

\begin{tabular}{|c|c|c|c|}
\hline \multirow{2}{*}{$\begin{array}{l}\text { Sample time } \\
\text { (days postharvest) }\end{array}$} & \multirow[b]{2}{*}{ Propagules/fruit in wash $\pm \mathbf{S E}^{\mathrm{a}}$} & \multicolumn{2}{|c|}{ Fruit isolations ( $\%$ positive) } \\
\hline & & Fruit $^{\text {b }}$ & Rind pieces \\
\hline \multicolumn{4}{|c|}{ First harvest 31 Mar 97} \\
\hline 2 & $7513 \pm 2103$ & $\mathrm{NT}^{\mathrm{d}}$ & NT \\
\hline 11 & $580 \pm 153$ & 10 & 0.31 \\
\hline 19 & $40 \pm 21$ & NT & NT \\
\hline \multicolumn{4}{|c|}{ Second harvest 18 Apr 97} \\
\hline 5 & $23 \pm 7$ & 15 & 0.44 \\
\hline
\end{tabular}

a Average number of propagules of $C$. acutatum recovered per fruit in a surface wash \pm the standard error of the mean, prior to washing, waxing, and fungicide treatment.

b Percentages of fruit with at least one isolation from the $403-\mathrm{mm}$ diameter rind plugs plated per fruit; fruit washed and waxed with $2,000 \mu \mathrm{g} / \mathrm{ml}$ each of thiabendazole and imazalil in the wax before isolations.

${ }^{c}$ Percentage of isolation of the total number of rind plugs.

${ }^{\mathrm{d}} \mathrm{NT}=$ Not tested.

Table 3. Inoculation of Robinson tangerines, navel oranges, and Ruby Red grapefruit with Colletotrichum gloeosporioides (C. g.) and C. acutatum (C. a.) to determine the ability of these two species to cause anthracnose and form quiescent infections on fruit (experiment 3)

\begin{tabular}{|c|c|c|c|c|c|c|}
\hline \multirow[b]{3}{*}{ Citrus species $^{\mathbf{b}}$} & \multirow[b]{3}{*}{ Fungal species $^{\mathbf{b}}$} & \multirow[b]{3}{*}{ Inoculation sites with lesions (\%) } & \multicolumn{4}{|c|}{ Reisolation $(\%)^{\mathrm{a}}$} \\
\hline & & & \multicolumn{2}{|c|}{ Lesions } & \multicolumn{2}{|c|}{ No lesions } \\
\hline & & & C. g. & C. a. & C. g. & C. a. \\
\hline \multirow[t]{3}{*}{ Robinson tangerines } & C. gloeosporioides & $55.0 \pm 10.4$ & 100.0 & 0.0 & $74.4 \pm 17.9$ & 0.0 \\
\hline & C. acutatum & 0.0 & $\ldots{ }^{\mathrm{c}}$ & & 0.0 & $63.3 \pm 6.0$ \\
\hline & Control & $3.3 \pm 3.3$ & 100.0 & 0.0 & $22.6 \pm 2.6$ & 0.0 \\
\hline \multirow[t]{3}{*}{ Navel oranges } & C. gloeosporioides & 0.0 & $\ldots$ & $\ldots$ & $53.8 \pm 13.8$ & 0.0 \\
\hline & C. acutatum & 0.0 & & & 0.0 & $51.3 \pm 4.3$ \\
\hline & Control & $6.7 \pm 3.5$ & 100.0 & 0.0 & $3.2 \pm 2.9$ & 0.0 \\
\hline \multirow[t]{3}{*}{ Red grapefruit } & C. gloeosporioides & 0.0 & $\ldots$ & $\ldots$ & $78.1 \pm 10.4$ & 0.0 \\
\hline & C. acutatum & 0.0 & $\ldots$ & $\ldots$ & 0.0 & $78.1 \pm 9.4$ \\
\hline & Control & $2.1 \pm 2.1$ & 0.0 & 0.0 & $38.0 \pm 9.1$ & 0.0 \\
\hline
\end{tabular}

${ }^{\mathrm{a}}$ Fruit was washed and waxed in a standard packinghouse operation prior to isolations; wax contained thiabendazole at 2,000 $\mu \mathrm{g} / \mathrm{ml}$.

${ }^{b}$ Three replicate humid chambers with 20 fruit each were used for Robinson tangerines; four replicates of 20 fruit each were used for navel oranges; and four replicates of 16 fruit each were used for Ruby Red grapefruit; two inoculation sites per fruit were used in all cases; means \pm standard error.

${ }^{\mathrm{c}}$ No lesions. 
Colletotrichum spp. were recovered from all of those fruit. All 25 isolates recovered from fruit from both groves were identified as $C$. gloeosporioides.

Natural infections in spring-harvested fruit. High populations of C. acutatum were recovered from washings of mature Valencia oranges harvested during active infections on the bloom (Table 4). However, those populations on untreated fruit held after harvest decreased about 10-fold for each 8- to 9-day period on fruit of storage. The number of propagules in washings were of the same order of magnitude at the third sample time of the first harvest as on those of fruit from the second harvest. Thus, populations on the fruit in the grove appeared to decline at the same rate as those on stored fruit. No anthracnose developed on any of these fruit.

C. acutatum was isolated from rind plugs from fruit that had been washed with SOPP and treated with imazalil and TBZ. This species was isolated from only about 10 to $15 \%$ of the fruit, then only from 1 to 2 plugs per fruit with less than $1 \%$ of the plugs yielding $C$. acutatum (Table 4).

Fruit from the second harvest which had been stored for 7 weeks showed some stem-end rind breakdown due to desiccation. Colletotrichum spp. colonizing affected areas of 21 of these fruit were isolated. All of the isolates recovered were identified as $C$. gloeosporioides.

\section{DISCUSSION}

In contrast to $C$. gloeosporioides, $C$. acutatum does not cause postharvest anthracnose on citrus. Even when high concentrations of conidia of $C$. acutatum were placed on localized wounded areas of the rind of Robinson tangerine, the most susceptible variety $(6,7)$, and the fruit treated with high concentrations of ethylene, little anthracnose developed. C. gloeosporioides was isolated from those few lesions formed, probably as the result of natural infections. There were low levels of natural infections of C. gloeosporioides in all three experiments. The application of benomyl to some of the trees the previous summer probably reduced the number of quiescent infections. Thorough washing of the fruit prior to inoculation probably removed many appressoria from the surface, thus further reducing natural infection $(6,7)$.

More that half of the Robinson tangerines inoculated with $C$. gloeosporioides developed anthracnose. No anthracnose developed on navel oranges or grapefruit as a result of inoculation. These varieties are less susceptible to anthracnose than Robinson tangerines and their rinds were probably sufficiently mature by the time the fruit was harvested to be resistant to disease development $(6,7)$. Sometimes $C$. gloeosporioides was recovered from a low to moderate percentage of the control fruit, but was not detected in fruit inoculated with $C$. acutatum. Recovery of $C$. gloeosporioides was probably prevented because the large amount of inoculum of C. acutatum suppressed the natural development of C. gloeosporioides.

When the navel oranges were harvested in the fall from groves which had severe PFD the previous spring, little anthracnose developed, even under favorable conditions. The failure to isolate $C$. acutatum from those anthracnose lesions provides further evidence that this species does not cause postharvest anthracnose.

High numbers of propagules of $C$. $a c u$ tatum were recovered from the surface of Valencia orange fruit harvested during an active PFD outbreak. The number of propagules declined rapidly without any treatment, suggesting that many of those propagules were conidia rather than quiescent infections formed from appressoria. However, quiescent infections were formed in high numbers on inoculated fruit, and some apparently also were formed on naturally exposed fruit. These infections appeared to be reduced but not eliminated by washing, waxing, and fungicide treatment. However, after long-term storage, only $C$. gloeosporioides was isolated from damaged fruit.

The possibility of transport of C. acutatum to areas free of PFD on commercial citrus fruit appears to be slight. Only in the case of Valencia oranges or grapefruit which might be harvested during bloom would there be any chance of contaminating the fruit. Many propagules would be removed or killed by normal washing, waxing, and fungicide treatment in the packinghouse. Quiescent infections would probably decline with time on fruit as they do on leaves in the grove (2), further reducing risk. Since appressoria of $C$. acutatum germinate directly without invasion of tissue to produce a few conidia $(3,12,15)$, rather than forming acervuli with abundant conidia, there would be little risk of spread even if fruit with quiescent infections were introduced to disease-free areas.
ACKNOWLEDGMENTS

We thank Melvin Chambers and Ana Ibañez for excellent technical assistance.

\section{LITERATURE CITED}

1. Agostini, J. P., and Timmer, L. W. 1992. Selective isolation procedures for differentiation of two strains of Colletotrichum gloeosporioides from citrus. Plant Dis. 76:1176-1178.

2. Agostini, J. P., and Timmer, L. W. 1994. Population dynamics and survival of strains of Colletotrichum gloeosporioides on citrus in Florida. Phytopathology 84:420-425.

3. Agostini, J. P., Timmer, L. W., and Mitchell, D. J. 1992. Morphological and pathological characteristics of strains of Colletotrichum gloeosporioides from citrus. Phytopathology 82:1277-1382.

4. Bernstein, B., Zehr, E. I., Dean, R. A., and Shabi, E. 1995. Characteristics of Colletotrichum from peach, apple, pecan, and other hosts. Plant Dis. 79:478-482.

5. Brown, A. E., Sreenivasaprasad, S., and Timmer, L. W. 1996. Molecular characterization of slow-growing orange and Key lime anthracnose strains of Colletotrichum from citrus as C. acutatum. Phytopathology 86:523527.

6. Brown, G. E. 1975. Factors affecting postharvest development of Colletotrichum gloeosporioides in citrus fruits. Phytopathology 65:404-409.

7. Brown, G. E., and Barmore, C. R. 1977. The effect of ethylene on susceptibility of Robinson tangerines to anthracnose. Phytopathology $67: 120-123$.

8. Freeman, S., and Katan, T. 1997. Identification of Colletotrichum species responsible for anthracnose and root necrosis of strawberry in Israel. Phytopathology 87:516-521.

9. Freeman, S., and Shabi, E. 1996. Cross-infection of subtropical and temperate fruits by Colletotrichum species from various hosts. Physiol. Mol. Plant Pathol. 49:395-404.

10. Knapp, J. L., ed. 1997. Florida Citrus Pest Management Guide. Univ. Fla. Inst. Food Agric. Sci. Publ. No. SP-43.

11. Sonoda, R. M., and Pelosi, R. R. 1988. Characteristics of Colletotrichum gloeosporioides from lesions on citrus blossoms in the Indian River of Florida. Proc. Fla. State Hortic. Soc. 101:36-38.

12. Timmer, L. W., Agostini, J. P., Zitko, S. E. and Zulfiqar, M. 1994. Postbloom fruit drop, an increasingly prevalent disease of citrus in the Americas. Plant Dis. 78:329-334.

13. Waller, J. M. 1992. Colletotrichum diseases of perennial and other cash crops. Pages 167185 in: Colletotrichum, Biology, Pathology and Control. J. A. Bailey and M. J. Jeger, eds. CAB International, Wallingford, UK.

14. Whiteside, J. O. 1988. Symptomless and quiescent infections by fungi. Page 30 in: Compendium of Citrus Diseases. J. O. Whiteside, S. M. Garnsey, and L. W. Timmer, eds. APS Press, St. Paul.

15. Zulfiqar, M., Brlansky, R. H., and Timmer, L. W. 1996. Infection of flower and vegetative tissues of citrus by Colletotrichum acutatum and C. gloeosporioides. Mycologia 88:121-128. 